\title{
Memórias de uma Socióloga Professora na Faculdade de Educação da UFC-Ceará (1986-2016)
}

\author{
Maria Juraci Maia Cavalcante \\ 'Universidade Federal do Ceará (UFC), Fortaleza/CE - Brasil
}

RESUMO - Memórias de uma Socióloga Professora na Faculdade de Educação da UFC-Ceará (1986-2016). Apresenta a experiência acadêmica de uma socióloga na Faculdade de Educação da Universidade Federal do Ceará (UFC), vista esta como espaço de interdisciplinaridade, concepção de projetos, grupos de pesquisa e formação docente. Tem apoio nas recomendações metodológicas de Justino Magalhães (2004) e suporte em registros de memórias de gestores e docentes da instituição enfocada, a exemplo de Antônio Martins Filho (1996) e Paulo Elpídio de Menezes Neto (2011), que têm componentes autobiográficos. Apresenta uma seleção de memórias e impressões docentes, desde o ano de 1986, quando a UFC e a autora contavam com 3 décadas de vida. Conclui que ambas estavam na fase jovem da vida, que alimenta sonhos desafiadores e criativos planos de futuro.

Palavras-chave: Instituição. História de Vida. Formação Docente. Educação. Memória.

ABSTRACT - Memoirs of a Sociologist Professor at the School of Education at UFC - Ceará (1986-2016). The paper presents the academic experience of a sociologist within the School of Education of Universidade Federal do Ceará, seen as an interdisciplinary space, of projects development, research groups and teacher training. It is based on the methodological recommendations of Justino Magalhães (2004) and is supported by records of memories from managers and teachers of the institution focused, like Antonio Martins Filho (1996) and Paul Elpídio de Menezes Neto (2011), which have autobiographical components. It presents a selection of teachers' memories and impressions since 1986, when UFC and the author were 30 years old. It concludes that both were in the young stage of life, nurturing challenging dreams and creative plans for the future.

Keywords: Institution. Life History. Teacher Training. Education. Memory.

Educação \& Realidade, Porto Alegre, v. 41, n. especial, p. 1465-1483, dez. 2016. 1465 http://dx.doi.org/10.1590/2175-623668267 


\section{Introdução}

Após o turbilhão de acontecimentos que culminaram com o suicídio do Presidente Getúlio Vargas, Antônio Martins Filho (1996b) nos mostra em suas memórias como a sonhada universidade cearense seria criada, a 16 de dezembro de 1954. Ele fora nomeado Reitor da Universidade do Ceará, no dia 18 de maio de 1955, como narra ele próprio, no livro História Abreviada da UFC, por ato de Café Filho, publicado no Diário Oficial da União. Martins Filho viaja apressado para a capital da República, sem ter tido tempo de escrever o seu discurso. Chegada a hora, inspirado em leituras de Ortega y Gasset ${ }^{1}$, ele aborda as missões da Universidade moderna, pautadas na famosa tríade do ensino, pesquisa e extensão; e diz do seu intuito de cooperar na solução dos problemas da economia e sociedade. Vejamos o que lera Martins Filho sobre o assunto:

Misión de la Universidad contém cinco capítulos, os dois primeiros tratam, respectivamente, do problema fundamental que envolve a Universidade e a aplicação do princípio da economia ao ensino. Considerando o limite do estudante para aprender, o desafio da Universidade, para Ortega, é oferecer um conteúdo compatível com o limite do estudante. Explicado isso, Ortega estabelece as tarefas básicas da instituição em ordem hierárquica: a) transmissão de cultura, b) a oferta do ensino profissional e c) a pesquisa científica. Nos dois capítulos subsequentes, Ortega distingue profissão de ciência e ciência de cultura. Finalmente, no último capítulo, dedica-se a explicar o papel indispensável da ciência na Universidade e o papel da Universidade na sociedade (Carvalho; Tomaz, 2015, p. 25).

Quantas águas rolaram entre a morte de Vargas, a posse de Martins Filho e a vida atual da República do Brasil! As duas épocas talvez tenham em comum a crise política, o vínculo partidário de governo com o setor do trabalho em disputa com o grupo liberal que lhe acua, a ambição externa sobre a riqueza petrolífera do País, o frágil apelo nacionalista; de diferença, ter havido a mudança de gênero do poder, em face de termos vivido a experiência de contar com a presença de uma mulher no cargo da presidência; e a falta de sustança do discurso político posto em litígio, em relação ao desenho de um projeto de inclusão social e nacional necessário ao efetivo desenvolvimento brasileiro. Lá se foram 60 anos e eis que a Universidade Federal do Ceará (UFC) há pouco se viu em tempo de escolha de um novo Reitor, depois de contextos políticos diversos, que oscilaram entre o populismo, a ditadura e a redemocratização; e de inúmeras gestões, marcadas pelo poder patriarcal. A galeria de ex-reitores instalada na escadaria do prédio da sua Reitoria é prova ilustrada da presença constante dos representantes do gênero masculino, herança do patriarcalismo que foi inquestionável em passado muito próximo $^{2}$.

1466 Educação \& Realidade, Porto Alegre, v. 41, n. especial, p. 1465-1483, dez. 2016. 
Ao relatar o percurso da UFC, António Martins Filho ${ }^{3}$ destaca a importância estratégica de uma das suas Unidades acadêmicas pelo papel que teve no planejamento da própria universidade, o então chamado Departamento de Educação e Cultura, núcleo fundador da área nessa instituição superior, afirmando que,

Aliás, não se tratava de um simples Departamento subordinado à Reitoria, mas, sim, de um órgão de cúpula, onde os projetos eram elaborados, com base numa concepção filosófica e num sentimento de pioneirismo que nos empolgava, constituindo, consequentemente, uma motivação para que o nosso trabalho em favor da instituição fosse sempre crescendo, com resultados positivos nas áreas de ensino, da pesquisa e da extensão (Martins Filho, 1996b, p. 84).

O recorte acima nos oferece o sentido inicial daquela, que viria a ser depois a Faculdade de Educação e Cultura, no processo de construção da Universidade do Ceará. Outro Reitor da UFC, que está entre os posteriores a Martins Filho, o professor Paulo Elpídio Menezes Neto (2011) também publicará suas memórias institucionais, em período mais recente, conforme apresento em algumas referências a seguir. Não é difícil relacionar essa forma de organização institucional com o modelo adotado pela USP.

A criação da USP constituiu um marco na história da educação e das ciências no Brasil, por iniciar uma nova fase no desenvolvimento científico e cultural do País. Criada sobre uma sólida base científica, sua fundação obedecia a um ambicioso projeto político e cultural, não somente para o estado de São Paulo, mas também para todo o Brasil. [...] Para realizar tais fins, a universidade organizou-se reunindo as escolas superiores e faculdades já existentes no estado de São Paulo [...] e criando a Faculdade de Filosofia, Ciências e Letras que seria o seu núcleo central, a 'cellula mater', na qual se encontravam todas as disciplinas básicas, responsáveis pela formação dos futuros quadros científicos e docentes do país [...] (Melfi; Motoyama, 2010, p. 409).

No ano de 1961, será criada a Faculdade de Filosofia, Ciências e Letras da UFC, que aproxima distintas áreas do conhecimento e professores com formação variada, onde "[...] reúnem-se, nessa nova unidade escolar, as licenciaturas, na sua formação pedagógica e os cursos de letras, pedagogia e geografia, então existentes ou em processo de instalação" (Menezes Neto, 2011, p. 91). Tratava-se de uma reforma institucional, modelada pela estrutura departamental mais integrada ao campo das humanidades, sendo esta formada pela área de Letras, Educação e Ciências Sociais, conforme nos explica Menezes Neto a seguir.

[...] Quanto ao Departamento de Educação, responsável pelo ensino das disciplinas pedagógicas e pelo Curso de

Educação \& Realidade, Porto Alegre, v. 41, n. especial, p. 1465-1483, dez. 2016. 1467 
graduação em Pedagogia, coubera-lhe assegurar a oferta regular das disciplinas da área de ciências sociais para vários cursos de graduação da universidade. Sociologia, introdução à economia, introdução à antropologia, história das ideias políticas e cultura brasileira figuravam nesse elenco de disciplinas, que não constituíam, necessariamente, parte integrante do currículo pleno de pedagogia.

Esta estrutura do Departamento de Educação duraria, segundo a citada fonte, até o ano de 1966. Em 1967, é criado um novo departamento para abrigar a área de Ciências Sociais, entre outras, em separado. Vale a pena destacar que o quadro de professores que a integrava era composto por uma diversidade de formação superior, ligada às áreas de história, geografia, direito, letras, antropologia, filosofia e agronomia. Contudo, a reforma universitária estava em curso, sendo efetivada pela Lei n. 5540 (Brasil, 1968).

Alexandre Tavares do Nascimento Lira (2012) retrata o processo que deu origem e corpo a essa reforma.

Em linhas gerais, a reforma foi um assunto de gabinete, o próprio presidente decretou o início dos trabalhos depois dos pareceres de uma comissão mista (MEC-USAID), cujas recomendações não foram colocadas a público e nomeou um grupo de trabalho de dez pessoas. Não houve debate aberto sobre a questão. A reforma e os meios de comunicação só serviram para divulgar os resultados. Os estudantes e os professores, na prática, não participaram do debate. O tecnicismo foi a concepção que norteou a reforma [...] (Lira, 2012, p. 3).

A partir dela, teria início o reinado do chamado "tecnicismo educacional”, separando áreas do conhecimento antes interligadas e, sobretudo, isolando a Educação do campo das Humanidades. Sabidamente, as Ciências Humanas resultaram de uma aproximação acumulativa das diferentes ciências que, aglutinadas, pretendiam oferecer, sobretudo, no século passado, uma leitura mais ampla das sociedades e dos mundos por onde elas transitam.

[...] durante todo o século XX, vários 'grandes paradigmas' se revezaram e imbricaram para forneces chaves explicativas: marxismo, psicanálise, culturalismo, estruturalismo, teoria de sistemas. Para os marxistas (e eles eram muitos), podia-se descodificar a sociedade, a História, a partir das suas bases econômicas; com a psicanálise, as nossas ações podiam revelar um sentido escondido: o das pulsões inconscientes; o estruturalismo queria revelar a estrutura oculta dos mitos, dos ritos e da sociedade. A História parecia ser um sentido; a Economia, leis; a sociedade, uma ordem; o indivíduo, um objetivo. Em suma, parecia haver coerência no mundo. Uma coerência muitas vezes escondida, mas que as Ciências Humanas tinham o dever de revelar (Dortier, 2009, p. 273-274).

1468 Educação \& Realidade, Porto Alegre, v. 41, n. especial, p. 1465-1483, dez. 2016. 
O modelo tecnicista aplicado à área de educação geraria um ambiente de restrição científica, associado à perseguição ideológica e política a professores e alunos, e adoção de uma visão psicológica e behaviorista de homem; este oscila entre ser visto, como sujeito ou na condição de mero objeto de ações externas.

[...] A tendência tecnicista foi introduzida por volta de 1968 na política educacional do regime militar, dando ao ensino brasileiro uma orientação sistêmica e tecnicista, baseada em princípios positivistas como racionalidade, eficiência e produtividade, com forte peso na formação técnica e no ensino profissionalizante. Duas leis são representativas dessa orientação, a Lei no 5.540/1970 e a Lei no 5692/1971 [...] (Libâneo; Oliveira; Toschi, 2012, p. 240).

A reforma dirigida por essa tendência se fazia presente no âmbito da UFC, em especial, no que se refere à sua unidade de educação.

O desmembramento do Departamento de Educação da Faculdade de Filosofia, Ciências e Letras, em 1966, com a constituição do Departamento de Ciências Sociais e Filosofia, ocorreu dois anos após a instalação do primeiro governo militar do Ciclo de 1964. Mal cicatrizadas as feridas abertas com as primeiras ações repressivas, redobraram os controles e a vigilância sobre a comunidade universitária [...] (Menezes Neto, 2011, p. 133).

Dessa forma, a área da Educação estava numa situação de grande controle político, sob uma racionalidade impregnada da teoria do capital humano, que perduraria por um tempo tido como longo, causando pressão e conflito de toda ordem, até o fim da ditadura militar, ocorrida nos primeiros anos da década de 1980 .

Estamos a seis décadas da criação da UFC e do seu Departamento de Educação. Este último seria alvo de algumas reformas, que foram alterando o seu papel no interior dessa universidade. Como vimos, o referido departamento começou por planejar a própria construção desta IES e abrigou a área diversificada das Ciências Humanas, antes de ser concebida como Faculdade de Educação, conforme está configurada na atualidade. A partir de um olhar retrospectivo, sabemos que as duas instituições e suas articulações acumulam protagonismos, testemunhos e acontecimentos políticos tão diversos que mereceriam um estudo histórico à parte. A universidade brasileira, aliás, em sua ainda curta existência, viveu períodos de democratização e de autoritarismo, em conformidade com o cenário político nacional, que ora favoreceria campanhas eleitorais e participação política, ora a formação de ambientes de conspiração e perseguição ideológica.

Foram centenas de professores e milhares de alunos que passaram pelas duas instituições em foco. Nesse sentido, reconstituir as suas histórias necessitaria da reunião de incontáveis relatos e registros do-

Educação \& Realidade, Porto Alegre, v. 41, n. especial, p. 1465-1483, dez. 2016. 1469 
cumentais e orais, além de depoimentos de vivos e mortos. Não sendo possível executar, no momento, um projeto de tão larga envergadura, vou me limitar a apresentar uma seleção de memórias e impressões, como professora da Faculdade de Educação, desde o ano de 1986, justamente, quando a UFC e eu tínhamos uns 30 anos de idade. Estávamos na melhor fase de nossos percursos, ambas impulsionadas por uma vontade de realização; uma disposição tão formidável e característica da fase jovem da vida, que alimenta sonhos desafiadores e criativos planos de presente e futuro.

\section{Os Anos 1980: a redemocratização e a politização da educação brasileira}

Quando, por obra do acaso, tomei conhecimento de que estavam abertas as inscrições para uma vaga de concurso para professor, na Faculdade de Educação da UFC, corria o ano de 1986. Eu me encontrava, então, no oitavo mês de gravidez de uma menina, a quem dei o nome luminoso de Gabriela, por sugestão do Bruno, meu bem amado primogênito. Tomei o programa de estudo como desafio, porque embora fosse licenciada em Ciências Sociais pela UFC, o meu conhecimento específico na área de Educação se limitava ao que eu estudara nas disciplinas pedagógicas daquela licenciatura, no ano de 1978. A lista de temáticas para estudo do referido concurso me pareceu bastante ampla. Envolvia, desde a didática geral, ao manuseio da metodologia de ensino nas primeiras séries do primeiro grau; alcançava também questões de maior abrangência sociológica, que indagavam sobre as bases políticas da educação e a ideologia presente no currículo escolar.

Como é, largamente, sabido, os anos 1980 pediam a redemocratização do Brasil e a politização da educação. Esta área, durante os 20 anos de ditadura militar, estivera presa ao escopo teórico do tecnicismo e o seu delineamento conceitual ligara-se a modelos de planejamento do centro capitalista. Isto porque, "a partir de 1964, acentuava-se a influência norte-americana no Brasil, com preeminência da cooperação com instituições acadêmicas dos Estados Unidos [...]” (Menezes Neto, 2011, p. 106).

Ao ser aprovada naquele concurso, o que foi motivo de grande surpresa minha - por estar concorrendo a uma única vaga com mais de uma dezena de pedagogos bem formados - entendi que me favorecera nesse resultado a minha formação como socióloga, em face da necessidade posta naquele momento político de adoção da perspectiva sociológica na formação de educadores. O curso que eu fizera ${ }^{4}$ oferecia algum domínio teórico considerado clássico. Este estava organizado com base no tripé fundacional dessa área, dado pelo funcionalismo positivista de Durkheim, pela abordagem fenomenológica e histórica de esferas diversas da sociedade moderna, criada por Max Weber; e vertente do marxismo, com sua crítica à economia política e ideologia burguesa,

1470 Educação \& Realidade, Porto Alegre, v. 41, n. especial, p. 1465-1483, dez. 2016. 
onde a educação ocupa significados distintos, tanto para a conservação da desigualdade, quanto para a sua demolição social.

Segundo dados oferecidos por Paulo Elpídio de Menezes Neto, ex-reitor da UFC, em estudo já citado acima, o curso de Ciências Sociais onde eu estive como aluna, entre 1975 e 1978, estava sob a influência da sociologia francesa, não por acaso, mas em função do acordo de cooperação internacional aberto por uma missão da UNESCO, iniciada em 1968, que favoreceu, na década seguinte, vários projetos de intercâmbio, pesquisa e pós-graduação. Como aluna de graduação, inicialmente, e do mestrado em Sociologia, entre 1983 e 1986, eu percebia essa proeminência acadêmica, que me levava a assistir a várias palestras de sociólogos e antropólogos franceses, como Jean Duvignaud, Georges Balandier, Remy Riand, Edgar Morin, Jean Ziegler [este é suíço, professor de Antropologia da Universidade de Genebra] e, por último, Michel Maffesoli. A participação desses cientistas sociais no nosso ambiente acadêmico nos convidava, obviamente, a leituras e vínculos teóricos bem estreitos com a sociologia francesa e o enfoque mais amplo das ciências humanas, tão caras ao ambiente acadêmico da França. Segundo informe de Eduardo Diatahy Bezerra de Menezes, professor do Departamento de Ciências Sociais da UFC e então Coordenador do seu curso de Pós-Graduação, "a partir da criação do Mestrado em Sociologia (1976) alguns jovens pesquisadores franceses ficaram mais tempo como professores visitantes, como Annie Guedez, Jean-Pierre Corbeau, Rémy Riand, Irène Nahoum, etc".

Contudo, vale salientar que uma parte dos meus professores estudara na França, parte no Ceará e sudeste do Brasil; e outra, nos Estados Unidos da América e na Alemanha. As diversas influências teóricas recebidas pelo corpo docente proporcionou-me, na segunda metade dos anos 1970, uma formação de cientista social de cunho mais abrangente, bem próxima do humanismo, da pesquisa antropológica e da crítica aos pressupostos da chamada sociologia do status quo, o que não nos impediu de conhecer, no interior das disciplinas cursadas, a teoria de sistemas de Talcott Parsons e Paul Baran, no âmbito da sociologia e da comunicação; assim como a tese de Immanuel Wallerstein, com o seu conceito de sistema-mundo moderno, uma abordagem econômica e histórica, com alto teor de crítica ao capitalismo colonialista e globalizado ${ }^{5}$.

O marxismo aparecia no estudo de Wallerstein, como possibilidade crítica, ao lado de outras correntes. Ainda que fosse proibido constar Marx em programas disciplinares de estudo, nos anos do regime militar do pós-64, era possível estudá-lo, na segunda metade dos anos 1970, junto a grupos de leitura alternativos, que se reuniam, à noite ou nas tardes de sábado, para discussão de textos considerados essenciais. Nos anos 1980, quando cursei o mestrado, Marx e seus seguidores já eram tema de disciplinas, recebiam atenção especial no campo das Ciências Sociais da UFC e alcançavam a área da Educação.

Educação \& Realidade, Porto Alegre, v. 41, n. especial, p. 1465-1483, dez. 2016. 1471 
Eu concluíra o mestrado em Sociologia do Desenvolvimento, em março de 1986. Seis meses depois, na condição de jovem socióloga, eu me vi entrando em território alheio. Ao ser contratada como docente na UFC, na sua Faculdade de Educação, eu passara a ser desafiada a estudar filosofia, psicologia do desenvolvimento, história das ideias pedagógicas e da educação. A atmosfera vigente era de debate e acirrada disputa política que se dava então entre tecnicistas e humanistas; ecléticos e histórico-críticos. Para os últimos, as aulas de didática-no curso de Pedagogia e nas Licenciaturas das demais áreas e cursos em ciências - eram eivadas do apelo crítico ao capitalismo e à teoria do capital humano. Adotavam uma atitude didática e política de valorização de alunos, enquanto sujeitos aprendizes e portadores de cultura e potencial consciência política; vistos como cidadãos e futuros profissionais capazes de contribuir para a mudança social. Paulo Freire era o nome mais comentado e inspirador da pedagogia crítica. Ele esteve presente na Faculdade de Educação da UFC em palestras memoráveis, que lotavam auditórios do Campus do Benfica. O centro Acadêmico do curso de Pedagogia reabrira com a redemocratização, usando o nome dele, em homenagem à sua proposta educacional libertária.

A Faculdade de Educação apresentava, quando de minha chegada, uma estrutura departamental tripartida - a qual vigora até os dias que correm - sob as seguintes designações: 1) Fundamentos da Educação; 2) Teoria e Prática do Ensino; 3) Estudos Especializados. No primeiro, estavam em maioria os docentes perfilados com o tecnicismo educacional, que vigorara durante o período ditatorial; no terceiro, havia uma mescla de tendências aglutinadas e divididas em disciplinas e áreas novas, sopradas pela redemocratização, que envolviam educação especial, movimentos sociais, organização social do trabalho e política educacional; os enfoques teóricos eram também variados, pois iam de estudos psicológicos de recorte cognitivo, passando pela sociologia francesa de Bourdieu, a educação de adultos ancorada em Paulo Freire; e chegando ao enfoque de Gramsci, no estudo das ideologias e dos intelectuais orgânicos, segundo conceitos extraídos do materialismo dialético e histórico.

Eu ficara lotada no departamento do meio, situado de certo modo entre dois extremos ideológicos, que recebia a alcunha de eclético. $\mathrm{O}$ Departamento de Teoria e Prática do Ensino, por estar ocupado com a parte mais pragmática da educação, precisava ensinar como fazer, como educar e construir a escola pública, no seu cotidiano. Além disso, esse Departamento era composto por alguns docentes que tinham recebido a tal formação tecnicista, mas também por outros, que transitaram do enfoque mais psicossocial da escola para aquele de linhagem sociológica de orientação mais crítica ${ }^{6}$.

Diante de tanta variedade temática, teórica e ideológica-presente na divisão departamental das matérias, preferências docentes, na grade curricular do curso de Pedagogia da UFC e no debate cotidiano inscri-

1472 Educação \& Realidade, Porto Alegre, v. 41, n. especial, p. 1465-1483, dez. 2016. 
to em reuniões colegiadas departamentais, conselhos daquela Unidade acadêmica e outros superiores; eleições para postos de chefia e coordenação da graduação e do curso de mestrado em educação - era forte demais e muito acirrada a disputa por lugares de discurso, formação e poder. Professores e alunos se agrupavam em distintas orientações científicas e políticas, sendo a educação palco de séria controvérsia e divergência, mudança de cadeiras e formação de alianças. O poder de gestores antes próximo do conservadorismo e controle político da ditadura militar e do tecnicismo educacional seria, pouco a pouco, substituído por integrantes e líderes de grupos portadores de discursos e práticas mais à esquerda e favoráveis à democratização da sociedade brasileira.

Entre 1986 e 1990, posso dizer que era assim que eu percebia e vivia o ambiente acadêmico e político da FACED-UFC. Nas aulas, os alunos, reorganizados ou não em suas entidades representativas, queriam entender a razão da mudança, também divididos em relação às diferenças postas para seus professores. Questionavam várias coisas: a estrutura curricular do curso, a escola pública como campo preferencial de estágio de docência, a participação da categoria estudantil no processo de reconstrução da UFC e do País, uma nova base legal e democratização da educação; assim como, o futuro profissional que lhes aguardava. Tudo estava em movimento, em ebulição, fermentando expectativas e atuações, tanto de alunos, quanto de professores; estes últimos se organizavam em sindicato próprio, reivindicavam melhorias salariais e participação política no interior da universidade e nas ruas, nos movimentos sociais, nos partidos políticos.

Situada entre a Sociologia e a Educação, eu recebia muitas lições novas sobre as possibilidades variadas postas naquele campo interdisciplinar. Estando numa faculdade de educação, eu passara a conviver com colegas de áreas diversas, formados em Pedagogia, Psicologia, Ciências, Filosofia, Ciências e Letras. Transitando entre tantas áreas, eu percebia que a Sociologia que trouxera na minha bagagem estava incorporando aos poucos outras preocupações e abordagens de estudo, como a epistemologia genética de Jean Piaget e o desenvolvimento do pensamento lógico abstrato; as recomendações e pesquisas de Emília Ferreiro sobre a psicogênese da língua escrita e os dilemas da alfabetização de crianças; estes últimos, estendidos a jovens e adultos; a história da pedagogia e os caminhos da política educacional no Brasil.

Entre encantada e perdida com tantas possibilidades de leitura e pesquisa, decidi-me por candidatar-me a uma vaga de doutorado no campo da Sociologia, no exterior. Ao saber ter sido contemplada com uma bolsa de estudos, após avaliação positiva do CNPq, deixei por quatro anos a Faculdade de Educação. Fui estudar na Universidade Carl Von Ossietsky - Oldenburger Universitaet, em Oldenburgo, no norte da Alemanha. Despedi-me de minhas gentis, acolhedoras e experientes colegas de departamento, formadas na boa tradição humanista da pedagogia, sem saber que, ao voltar da Europa, lamentavelmente, elas já

Educação \& Realidade, Porto Alegre, v. 41, n. especial, p. 1465-1483, dez. 2016. 1473 
estariam aposentadas em sua maioria, sendo o departamento de Teoria e Prática do Ensino em grande parte renovado por novos docentes, alguns deles formados na própria FACED-UFC.

\section{Docência na Pós-Graduação: o seminário de educação brasileira}

Foram quatro anos e meio de ausência, período em que a UFC e a sociedade brasileira viveram muitas mudanças. Ao voltar do meu curso de doutorado, onde me deparara com outro ambiente acadêmico, ligado à tradição científica e cultural alemã, eu viveria um novo desafio de adaptação. Na Alemanha eu desenvolvera uma investigação sobre a história social da migração de jovens e famílias cearenses, no período de um século, demarcado pela grade seca de 1877 e a transamazônica, nos anos $1970^{7}$; essa experiência me ligara ainda mais estreitamente ao campo interdisciplinar da Sociologia, História e Educação.

Quando fui vinculada, na condição de jovem doutora, em 1995, ao Programa de Pós-Graduação em Educação, comecei por dar aulas de metodologia de pesquisa social e educacional, em substituição a uma ex-professora minha, do Departamento de Ciências Sociais, que, infelizmente, adoecera súbita e gravemente. Foi para mim uma difícil tarefa, por ser ela uma especialista naquela área e cientista muito experiente, muito embora, o pior de tudo tenha sido receber a notícia de sua morte, poucos meses depois.

Em paralelo, comecei a definir um novo projeto de pesquisa, com vistas a justificar a minha inserção como investigadora na área da história da educação brasileira. A pesquisa realizada teve por tema a reforma educacional de 1922, no Ceará, a qual foi defendida em concurso a que me submeti para vaga de professora titular do Departamento de Estudos Especializados, na área de Política educacional, em 1998. O resultado colhido, referido ao final, foi publicado pela editora da UFC, no ano de 2000.

A minha ligação com o Seminário de Educação Brasileira (SEB) teve início entre os anos de 1999 e 2000, quando fui convidada a dividi-lo, na condição de colaboradora, com o meu experiente colega, Prof. Jacques Therrien. Foi o começo de uma experiência de docência que me marcaria profundamente, pois nele, eu encontrava uma justificativa de pesquisa importante para fortalecer a minha escolha de área e posterior evolução acadêmica, como professora, investigadora e orientadora de mestrado e doutorado.

A pergunta que eu me fazia estava ligada à historicidade da educação brasileira e cearense, ao lidar com uma bibliografia que herdara dos que me precederam e dirigiram aquele seminário, onde a história educacional era entendida como leitura de estudos já consolidados, que representavam uma produção restrita ao ordenamento da educação no sudeste brasileiro. Já expus o meu percurso como professora desse

1474 Educação \& Realidade, Porto Alegre, v. 41, n. especial, p. 1465-1483, dez. 2016. 
Seminário em publicações anteriores, como é o caso da coletânea organizada por Anamaria Gonçalves Bueno de Freitas e outros (2011), publicada pela UFAL, onde traço as tendências do ensino nessa área, nas décadas de 1980 e 1990, que passam da tradição de leitura de manuais e livros já consagrados, ao desenvolvimento de projetos investigativos sobre a história da educação cearense e brasileira.

O Seminário de Educação Brasileira (SEB) continua a ser hoje o lugar de integração curricular de todos os alunos de mestrado e doutorado que são matriculados no Programa de Pós-Graduação em Educação da UFC, sendo obrigatório cursá-lo porque intenciona oferecer um ponto de partida compartilhado a um grupo interdisciplinar de mestrandos e doutorandos, que traz percursos institucionais de trabalho, experiências formativas e expectativas profissionais distintas. Afinal, pensar a Educação Brasileira para interesses tão variados e múltiplos recomenda uma abordagem pautada na interdisciplinaridade.

Por essa razão, precisamos, antes de tudo, oferecer algumas sugestões teóricas do campo entrelaçado da sociologia e da história, da psicologia e da economia, das ciências da natureza e da epistemologia, que nos favoreçam entender a complexidade do campo da educação em geral, e da educação brasileira, em particular, no interior da chamada modernidade e pós-modernidade.

Trata-se, afinal, de uma área de estudos, que envolve diferentes dimensões temporais e espaciais, protagonismos políticos e sociais, relações internacionais e construção nacional; além de recortes temáticos diversos e infinitas possibilidades de leitura.

O importante é salientar que o referido seminário favoreceu a minha inserção, concepção e envolvimento com projetos e eventos de pesquisa na área de História educacional, tanto nacionais, quanto internacionais. Outro aspecto refere-se à metodologia de estudos que passei a desenvolver com os alunos do SEB, por convidá-los a realizar análise de estudos consagrados, busca de fontes em acervos públicos, escritas de memórias sobre seus processos familiares e escolares de educação. Nesse sentido, o Seminário adquiriu significado de laboratório de pesquisa e estimulou-me e ao conjunto de alunos a pensar e a entender a educação como processo investigativo.

Em 2015, o que apresentamos nesse seminário, como proposta de estudos, foi fruto de uma escolha baseada em nossa experiência de docência, nos últimos quinze anos. Com ela aprendemos, que mais importante do que operar conteúdos, é buscar estimular a vontade de pensar a educação brasileira, mediante amplos processos históricos e desafios contemporâneos. Este Seminário pressupõe que, dessa maneira, podemos melhor captar a dinâmica política e cultural da educação e vislumbrar horizontes mais criativos e propositivos de investigação e atuação como educadores.

Educação \& Realidade, Porto Alegre, v. 41, n. especial, p. 1465-1483, dez. 2016. 1475 


\section{A Semeadura do Campo da História Educacional}

Conforme mencionei no tópico anterior, a primeira semeadura partiu do projeto de pesquisa sobre a história da reforma educacional de 1922 no Ceará, que integra um conjunto de reformas do movimento Escola Nova, iniciadas no Brasil, no período da Primeira República. Dessa experiência investigativa resultou uma tese, um livro, um grupo de pesquisa e um evento anual. Ao receber mestrandos e doutorandos interessados em pesquisar a nossa história e memória educacional, pudemos estimular uma produção considerável de estudos na área, parte da qual foi publicada em coletâneas e livros em separado, pela editora da UFC, entre 2000 e $2015^{8}$, conforme consta ao final em nossas referências bibliográficas, pois não haveria aqui espaço para tratar de todos os estudos aglutinados no referido grupo ${ }^{9}$.

O percurso do referido grupo e/ou linha de pesquisa pode ser dividido em dois períodos: 1) de 2002 a 2010, ocupado com projetos de pesquisa voltados para a história educacional do Ceará; 2 ) o que começa em 2011, quando o foco das pesquisas do grupo se expande, adota uma perspectiva internacional, em especial, ligada à relação Brasil-Portugal. Favoreceu esta última configuração do grupo o Estágio Pós-Doutoral que realizei, no período de 2006-2007, junto à Faculdade de Psicologia e Ciências da Educação da Universidade de Lisboa, na área de História da Educação, sob a liderança do professor António Nóvoa, e supervisão do professor Justino Magalhães.

A abertura da Linha de História da Educação Comparada (LHEC), em março de 2011, se deve a uma reorientação da nossa perspectiva teórico-metodológica. Esta tem relação e faz, ao mesmo tempo, uma ruptura com o que pesquisávamos, anteriormente, quando criamos e desenvolvemos a Linha História e Memória da Educação, entre 2002 e 2009, com projetos de foco local e conexão nacional, com o intuito de compor uma produção e manual de nossa história educacional para o ensino dessa matéria e contribuir para a formação docente na área. A LHEC tem por base a nossa experiência paralela de formação, por meio de alguns dos nossos projetos de investigação, desenvolvidos na Alemanha - Tese de Doutorado/Universidade de Oldenburgo (1990/1995); Pós-Doutorado, na Alemanha/Universidade de Colônia (1999) e, em Portugal/Universidade de Lisboa (2006/2007); e como investigadora visitante, contratada pela Universidade de Lisboa (2009/2010). Neste último período, formulei um novo projeto de investigação sobre a volta e o papel educativo dos Jesuítas Portugueses ao Nordeste do Brasil, no século XX, com o qual recebi uma bolsa de produtividade em pesquisa do CNPq, para o período 2011-2014, renovada depois para 2014-2017.

A dimensão internacional firmada na LHEC envolve também algumas experiências anteriores de Orientação de teses de Doutorado sobre o Japão (2005) e a Itália (2006); por último, liga-se a uma viagem de intercâmbio à China, junto à Universidade de Shangai e visita à Uni-

1476 Educação \& Realidade, Porto Alegre, v. 41, n. especial, p. 1465-1483, dez. 2016. 
versidade de Pequim, como representante da UFC, que nos estimulou ao estudo mais sistemático da história da educação na Ásia, a partir das missões jesuíticas.

Voltando ao campo do ensino, no Programa de Pós-graduação em Educação da UFC, em linhas gerais, vale ressaltar que o SEB foi estruturado com vistas a aprofundar algumas temáticas afetas à História da Educação Brasileira. Junto a esse seminário, acumulo uma experiência de 15 anos de percurso. Tem sido o meu intuito estabelecer vínculos mais estreitos com as histórias e políticas nacionais de educação de outros países, de quem temos recebido forte influência ou com quem reconhecemos ligações históricas e culturais; seja por meio da circulação de ideias pedagógicas, seja dos modelos políticos de organização dos sistemas escolares nacionais, da recepção de projetos de pesquisa dos nossos alunos e alunas, a exemplo dos seguintes países: Portugal, França, Alemanha, Itália, Estados Unidos, Argentina, Angola e Guiné-Bissau. São balizas coordenadas de ensino de Educação Brasileira vinculadas ao que estudo e investigo com o grupo que compõe a nossa Linha de Pesquisa (LHEC). Tem como objetivo geral aprofundar algumas temáticas afetas à História da Educação Brasileira e à nossa Educação contemporânea, a partir de uma perspectiva internacional. Tal abordagem envolve as histórias de vários outros países, de quem temos recebido forte influência, como parte de um sistema mundial, seja por meio da circulação de ideias pedagógicas, seja por meio da adoção de modelos culturais e/ou políticos de organização dos sistemas escolares e educacionais nacionais.

No curso de Pedagogia da FACED-UFC, na última década, estive ocupada com o ensino de Autobiografia e Educação, Metodologia de Pesquisa e Política Educacional. São interconexões e desdobramentos das atividades de ensino e pesquisa desenvolvidas no âmbito da Pós-graduação, onde pude, todavia, com maior autonomia e liberdade realizar projetos, edição de livros e eventos, orientações de bolsistas PIBIC, e de alunos em pós-graduação.

\section{Considerações Finais}

Cheguei à Faculdade de Educação da UFC como socióloga, conforme anunciei logo de início e acredito não ser demais repetir e enfatizar, porque trata de uma prática de interdisciplinaridade tão cara à área educacional. Por ser a educação um campo multidisciplinar e submetido a interfaces desafiadoras, encontrei, naquele ambiente acadêmico, de certo modo, condições favoráveis para desenvolver um plano de estudo e investigação que tem me ocupado de forma intensa e construtiva.

Por outro lado, devo ressaltar que foi preciso enfrentar visões internas distintas, quanto ao significado da área de educação e de gestão acadêmica, que poderia, resumidamente, assim classificar: 1) a visão

Educação \& Realidade, Porto Alegre, v. 41, n. especial, p. 1465-1483, dez. 2016. 1477 
de alguns pedagogos mais fechados em si mesmos, que adotam entendimento corporativista, herdeiro do tecnicismo educacional em vigor, durante o período ditatorial e/ou associado com novos aliados interessados na proximidade e partilha do poder de gestão; 2) a ótica dos que chegam vindos de outras áreas, como a sociologia, a psicologia e a matemática, que são, por vezes, alvo de rejeição e obstrução acadêmica, por parte do grupo que acredita - por pertença de formação à área da pedagogia e/ou por atuação na gestão acadêmica da área de educação - ser um sujeito mais autêntico, herdeiro, discípulo e porta-voz de mais de meio século de história da Faculdade de Educação da UFC ${ }^{10}$.

Afora tais relações de teor interpessoal e micropolítico - revelador de uma posição, por vezes, desconfortável em relação ao aspecto da interdisciplinaridade e da internacionalidade, como parte indissociável da área pedagógica - devo ressaltar os aspectos mais favoráveis dessa experiência institucional. Não obstante, foi da Faculdade de Educação da UFC que parti e pude realizar voos mais altaneiros para realizar o meu Doutorado (1990-1995) e Pós-Doutorado (1999), na Alemanha; e na década seguinte, para um segundo Estágio Pós-Doutoral em Portugal (2006-2007). A Sociologia que estava na base da minha formação, foi abrindo espaço para novas interlocuções com várias áreas das chamadas Ciências Humanas. Ao aliar a atividade de ensino de graduação e pós-graduação, com pesquisa e formação de educadores em três níveis pude alargar meus horizontes intelectuais, acadêmicos e profissionais, num percurso de evolução e rendimento ascendente, tanto no plano individual, quanto grupal, em relação ao convívio com colegas receptivos e aos alunos que ajudei a formar, como educadores sensíveis à pesquisa no campo interconectado da história e da educação. Não poderia aqui detalhar a minha experiência de ensino e orientação, em função da exiguidade de espaço e necessidade de construção de outra digressão de memória.

A atividade de extensão ficou circunscrita à realização dos nossos eventos anuais de pesquisa na área da História educacional, que se tornaram itinerantes, nos colocaram em contato com a realidade educacional interiorana do Ceará e nos desafiaram a desenvolver projetos de pesquisa sobre a história da organização de instituições e protagonismos educacionais nas cidades menores, nas diversas microrregiões cearenses de norte a sul, de leste a oeste desta unidade federativa.

Ao contar com o apoio de inúmeras prefeituras e secretarias municipais de educação para a realização dos nossos Encontros e Congressos de História da Educação do Ceará, no período de 2002 e 2015, nós aceitamos ofertar vagas para o professorado da rede local, para que participassem deles, juntamente com alunos e professores com formação acadêmica e treinados em pesquisa social, histórica e educacional. Desse convívio e possibilidade de oferecer atividades - como minicursos, conferências, mesas de palestras, comunicações orais, apresentação de pôster, lançamentos de livros e atividades culturais - consideradas 
como sendo típicas do nosso fazer acadêmico, temos podido contribuir com a chamada educação ou formação permanente, estabelecer um contato mais estreito com a dinâmica e problemática do ensino básico em diversos municípios cearenses e entender a dificuldade que esses professores têm de desenvolver projetos de pesquisa, como parte regular de sua ação profissional docente.

Considero ser interessante observar que os alunos e alunas da FACED-UFC, nos cursos de graduação, no turno diurno e noturno, apresentem, por vezes, idêntica dificuldade, justamente porque começam a estagiar e/ou a trabalhar na área de ensino privado ou público, logo que cumprem os dois primeiros semestres de estudos. Esta busca pela prática pedagógica e inserção precoce do mercado de trabalho retira a possibilidade de que a maioria deles se ocupe com atividades de pesquisa e extensão universitária, o que percebemos com maior clareza, quando convocamos estudantes para a seleção de bolsistas de iniciação científica. São poucos os candidatos que aparecem para se ocupar com tais bolsas, alegando os demais falta de disponibilidade e tempo. Isto evidencia que a docência é tão absorvente que não comporta ser exercida em paralelo com a pesquisa e a extensão?

As Faculdades de Educação de outras universidades enfrentam, certamente, dificuldades similares, o que indica a necessidade de realização de levantamentos de dados e avaliações sobre o lugar da pesquisa na formação de docentes. A relevância desse debate está no reconhecimento de que a formação de professores requer a articulação com a atividade investigativa para que possa alimentar na própria ação pedagógica dos mestres e dos seus alunos o interesse e a necessidade de pesquisa. No meu caso, estar numa Faculdade de Educação, na condição docente, sendo socióloga, que já trazia algum treinamento em pesquisa social, me propiciou um engajamento intenso e muito envolvente nessa área e na formação de um grupo de mestres e doutores preocupados com o passado, o presente e o futuro da educação, no Brasil e no mundo!

Está claro que uma visão mais abrangente da Faculdade de Educação em foco - que deveria levar em consideração, outras experiências, percursos e olhares - poderia nos oferecer um retrato mais fiel e enriquecedor desta unidade acadêmica da Universidade Federal do Ceará, a começar pelo estudo histórico do currículo dos cursos de Pedagogia diurno e noturno, bem como de mestrado e doutorado em Educação brasileira, que formam o seu Programa de Pós-Graduação, o qual tem raio de ação espacial e social considerável na região nordeste, abriga diferentes linhas de pesquisa e contribuiu desde a sua fundação para a formação docente, política, científica e técnica de centenas de profissionais de diversos campos do conhecimento.

O que apresento aqui é um relato pequeno da minha vivência pessoal e grupal. Passaram-se três décadas desde a minha entrada como jovem docente. A menininha que eu trazia comigo na barriga, quando prestei concurso para professora da Faculdade de Educação da UFC,

Educação \& Realidade, Porto Alegre, v. 41, n. especial, p. 1465-1483, dez. 2016. 1479 
completa neste ano tinta anos de idade, já está casada e fortalece cada vez mais a sua inserção profissional na área de humanidades. Afinal, também ela e seu irmão, Bruno, que se formou economista, eivado de humanismo idealista, passaram a vida vendo a mãe a estudar, a viajar e a pesquisar o passado, o presente e o futuro da sociedade e educação brasileira. Eles me dizem sempre que a nossa casa e vida familiar era bem mais parecida com uma biblioteca e uma escola, pois havia livros, mesas de estudo e malas, por todos os lados, que materializavam ocupações sem fim ligadas com a história, sociologia e educação. Eu não lhes tiro a razão, pois, diferentemente de Pablo Neruda (1904-1973) ${ }^{11}$, confesso que, na condição de cientista social e professora investigadora de uma Faculdade de Educação, li e escrevi mais do que vivi! São leituras e saberes que carregarei comigo para sempre, sobretudo, quando não estiver mais ali engajada em atividades acadêmicas, que, reconhecidamente, ampliaram a minha visão de educação e do mundo.

Recebido em 27 de agosto de 2016 Aprovado em 21 de outubro de 2016

\section{Notas}

1 O texto lido foi, muito provavelmente, o famoso Missão da Universidade (1930), de autoria do erudito e polêmico filósofo espanhol, José Ortega y Gasset (18831955), que traz uma indicação do sentido histórico e contextualizado da ideia de instituição educacional superior, ver Ortega Y Gasset (1930). Como sabemos, instituições de ensino são lugares de reflexão e investigação privilegiados, pois abrigam e materializam projetos políticos e societários mais abrangentes, que permitem ligações diversas, entre memórias e arquivos, agentes e modelos de gestão e currículo, conforme chama atenção Justino Pereira Magalhães, em seus estudos. Sobre a conceituação por ele proposta, que é fonte de inspiração e guia metodológico nessa área, ver Magalhães (2004).

2 Os três primeiros parágrafos deste artigo foram publicados, em parte, no caderno Opinião do jornal O Povo, ver Cavalcante (2015b).

3 O Reitor fundador da UFC nasceu na cidade do Crato, no sul do Ceará, em 1904, e faleceu em Fortaleza, no ano de 2002. Antes de ser Reitor, foi professor da Faculdade de Direito do Ceará, onde tomou para si a missão de criação da primeira universidade cearense. Dedicou-se à edição de livros e às suas memórias, depois de afastado da sua função. Tratou também da história da UFC, ver Martins Filho (1996a).

4 Sobre a história desse Curso de Ciências Sociais, ver Haguette (1991).

5 Ver: Wallerstein (1974a; 1974b).

6 Sobre a história pedagógica da FACED-UFC, ver Fernandes (1990).

$7 \mathrm{O}$ resultado da pesquisa que fundamentou a Tese foi depois publicado, no mesmo ano do exame final, sob o título "Die sozio-historischen Grundlagen der Entstehung einer migratorischen Tradition in Nordostenbrasilien: zur raumlichen Mobilitaet von laendlichen Familien und JungenLeute, dargestellt am Beispiel Cearás". Frankfurt am Main, IKO - Verlag fuer Interkulturellen Kommunikation, 1995.

1480 Educação \& Realidade, Porto Alegre, v. 41, n. especial, p. 1465-1483, dez. 2016. 
8 Ver a lista de publicações aqui referida: Almeida (2013), Bastos; Cavalcante (2009), Cavalcante (2000), (2002) e (2008); Holanda; Morato (2016); as coletâneas da LHEC, organizadas por Cavalcante et al., em (2003), (2005), (2008), (2009), (2011), (2012), (2013), (2014), (2015).

9 Ver Cavalcante (2009b).

10 A este respeito, ver Brandão; Maciel; Bezerra (2014).

11 Ver Neruda (1978).

\section{Referências}

ALMEIDA, Núbia Ferreira. O Colégio Salesiano em Juazeiro do Norte e o Projeto Educacional do Padre Cícero. Fortaleza: Edições UFC, 2013.

BASTOS, Maria Helena Câmara; CAVALCANTE, Maria Juraci maia (Org.). O Curso de Lourenço Filho na Escola Normal do Ceará. Campinas: Alínea, 2009.

BRANDÃO, Maria de Lourdes Peixoto; MACIEL, Terezinha de Jesus Pinheiro; BEZERRA, José Arimatea Barros (Org.). Pedagogia UFC 50 anos: narrativas de uma história (1963-2013). Fortaleza: Edições UFC, 2014.

BRASIL, Lei n 5540 , de 28 de novembro de 1968. Fixa normas de organização e funcionamento do ensino superior e sua articulação com a escola média, e dá outras providências. Diário Oficial [da República Federativa do Brasil], Brasília, DF, v. 7, 29 nov. 1968. Seção I. P. 10369.

CARVALHO, José Maurício de; TOMAZ, Mauro Sérgio de Carvalho. Ortega Y Gasset: a filosofia e a universidade. Revista Brasileira de Educação e Cultura, Minas Gerais, Centro de Ensino Superior de São Gotardo, n. XI, p. 19-38, jan./ jun. 2015. Disponível em: <http://periodicos.cesg.edu.br/index.php/educacaoecultura/article/view/202/279>. Acesso em: 09 set. 2016.

CAVALCANTE, Maria Juraci Maia. João Hippolyto de Azevedo e Sá. O Espírito da Reforma Educacional de 1922 no Ceará. Fortaleza: Edições UFC, 2000 (Com Prefácio de Eduardo Diatahy Bezerra de Menezes).

CAVAlCANTE, Maria Juraci Maia (Org.). História e Memória da Educação no Ceará. Fortaleza, Edições UFC, 2002.

CAVALCANTE, Maria Juraci Maia. A Universidade Federal do Ceará como Instituição Cinquentenária: protagonistas e filosofias presentes nos discursos e ações em prol da sua criação. In: História da Educação: instituições, protagonistas e práticas. Fortaleza: Editora da UFC, 2005. P. 277-296.

CAVAlCANTE, Maria Juraci Maia. História Educacional de Portugal: discurso, cronologia e comparação. Um ensaio de crítica histórica. Fortaleza, Edições UFC, 2008.

CAVALCANTE, Maria Juraci Maia. Tendências do Ensino e da Pesquisa no Ceará no Campo da História da Educação. In: GATTI JUNIOR, Décio e outros (Org.). O Ensino de História da Educação em Perspectiva Internacional. Uberlândia: EDUFU, 2009b. P. 190-211.

CAVALCANTE, Maria Juraci Maia. O Ensino de História da Educação; da tradição dos manuais aos recortes temáticos, temporais e espaciais, sob novos protagonismos. In: FREITAS, Anamaria Gonçalves Bueno de e outros (Org.). O Ensino e a Pesquisa em História da Educação. Maceió: EDUFAL, 2011. P. 184-215.

$\overline{\text { Educação \& Realidade, Porto Alegre, v. 41, n. especial, p. 1465-1483, dez. 2016. } 1481}$ 
CAVALCANTE, Maria Juraci Maia. Uma Instituição Sexagenária. O Povo, Fortaleza, jun. 2015b. Disponível em: <http://www.opovo.com.br/app/opovo/opiniao/2015/06/29/noticiasjornalopiniao,3461574/uma-instituicao-sexagenaria. shtml>. Acesso em: 07 set. 2016.

CAVALCANTE, Maria Juraci Maia et al. (Org.). História da Educação - Vitrais da Memória: lugares, imagens e práticas culturais. Fortaleza: Edições UFC, 2008.

CAVALCANTE, Maria Juraci Maia et al. (Org.). Escolas e Culturas: políticas, tempos e territórios de ações educacionais. Fortaleza: Edições UFC, 2009a.

CAVALCANTE, Maria Juraci Maia et al. (Org.). História da Educação Comparada: discursos, ritos e símbolos da educação popular, cívica e religiosa. Fortaleza: Edições UFC, 2011.

CAVALCANTE, Maria Juraci Maia et al. (Org.). História da Educação: república, escola, religião. Fortaleza: Edições UFC, 2012. (Coleção História da Educação).

CAVALCANTE, Maria Juraci Maia et al. (Org.). História da Educação Comparada: missões, expedições, instituições e intercâmbios. Fortaleza: Edições UFC, 2013. (Coleção História da Educação).

CAVALCANTE, Maria Juraci Maia et al. (Org.). Afeto, Razão e Fé: caminhos e mundos da história da Educação. Fortaleza: Edições UFC, 2014. (Coleção História da Educação).

CAVALCANTE, Maria Juraci Maia et al. (Org.). Histórias de Mulheres: amor, violência e educação. Fortaleza: Edições UFC, 2015a. (Coleção História da Educação).

CAVALCANTE, Maria Juraci Maia; José A. B. BEZERRA (Org.). Biografias, Instituições, Ideias, Experiências e Politicas Educacionais. Fortaleza: Editora da UFC, 2003.

CAVALCANTE, Maria Juraci Maia; José Edvar Costa ARAÚJO e outros (Org.). História da Educação: instituições, protagonistas e práticas. Fortaleza: Editora da UFC, 2005.

DORTIER, Jean-François. Uma História das Ciências Humanas. Trad. Carla Gamboa e Hélder Viçoso. Lisboa: Edições Texto\&Grafia, 2009.

FERNANDES, Maria Estrela Araújo. Recuperando a História Pedagógico-social do Curso de Pedagogia da UFC: competência técnica e/ou compromisso político. 1990. Fortaleza, Dissertação (Mestrado em Educação) - Universidade Federal do Ceará, Fortaleza, 1990.

FREITAS, Anamaria Gonçalves Bueno de et al. (Org.). O Ensino e a Pesquisa em História da Educação. Maceió: EDUFAL, 2011.

HAGUETTE, Teresa Maria Frota (Org.). Memória das Ciências Sociais na UFC. Fortaleza: Edições UFC, 1991.

HOLANDA, Patrícia Helena Carvalho; MORATO, Pedro Jorge Parrot (Org.). Pedagogia Terapêutica: diálogos e estudos luso-brasileiros sobre João dos Santos. Fortaleza: Edições UFC, 2016.

LIBÂNEO, José Carlos; OLIVEIRA, João Ferreira de; TOSCHI, Mirza Seabra. Educação Escolar - Políticas, Estrutura, Organização. São Paulo: Cortez, 2012.

LIRA, Alexandre Tavares do Nascimento. As bases da Reforma Universitária da ditadura militar no Brasil. In: ANAIS DO XV Encontro Regional de História da ANPUH, Rio de Janeiro: 2012. Disponível em: <http://www.encontro2012. rj.anpuh.org/resources/anais/15/1338430408_ARQUIVO_AsbasesdaReformaUniversitariadaditaduramilitarnoBrasil.pdf>. Acesso em: 07 set. 2016.

1482 Educação \& Realidade, Porto Alegre, v. 41, n. especial, p. 1465-1483, dez. 2016. 
MAGALHÃES, Justino Pereira. Tecendo Nexos: história das instituições educativas. Bragança Paulista: Editora Universitária São Francisco, 2004.

MARTINS FILHO, António. História Abreviada da UFC. Fortaleza: Casa José de Alencar/Programa Editorial, 1996b. (Coleção Alagadiço Novo, 75).

MARTINS FILHO, António. O Universal pelo Regional: definição de uma política universitária. Fortaleza: Imprensa Universitária do Ceará, 1996a.

MELFI, Adolpho; MOTOYAMA, Shozo. O Ensino Superior no Brasil. In: A Universidade: uma história ilustrada. São Paulo: Banco Santander/Turner, 2010. P. 403-429.

MENEZES NETO, Paulo Elpídio de. O Ceará e suas Universidades. Fortaleza: Oficina da Palavra, 2011.

NERUDA, Pablo. Confesso Que Vivi. São Paulo: DIFEL, 1978.

ORTEGA Y GASSET, José. Misión de la Universidad. Revista de Ocident, Madrid, v. 4, p. 315-353, 1930.

WALLERSTEIN, Immanuel. O Sistema Mundial Moderno. v. I: a agricultura capitalista e as origens da economia-mundo europeia no século XVI. Porto: Ed. Afrontamentos, 1974a.

WALLERSTEIN, Immanuel. O Sistema Mundial Moderno. v. II: o mercantilismo e a consolidação da economia-mundo europeia, 1600-1750. Porto: Ed. Afrontamentos, 1974b.

Maria Juraci Maia Cavalcante é graduada e Mestre em Sociologia (UFC). Doutorada em Ciências Econômicas e Sociais - na Carl von Ossietsky Universitaet - Oldenburger Universitaet/Alemanha. Pós-Doutorada em Política Educacional (Universidade de Colônia/Alemanha); e em História Educacional de Portugal (Universidade de Lisboa). Professora Titular da Universidade Federal do Ceará. Investigadora da LHEC-UFC. Bolsista Produtividade CNPq.

E-mail: juraci.cavalcante@ufc.br 
